\title{
The shoulder girdle disc
}

\author{
DOUGLAS G. PHILLIPS \\ From the Department of Neurological Surgery, Frenchay Hospital, Bristol
}

SYNOPSIS Weakness and wasting of shoulder girdle muscles occurred in 40 cases of cervical spondylosis at the level C 3/4 intervertebral space with spinal cord, and lower with nerve root compression. Often there was no sensory loss. Prompt recovery followed Cloward's operation in more than half the cases. The pathogenesis and the need for early diagnosis and radical treatment of the condition are considered.

Phillips (1975) noted that the shoulder muscles, including spinati and deltoids, were affected in a minority of both groups of cases of neurological disorder-myelopathy and brachial neuritisassociated with cervical spondylosis (Figs. 1 and 2). Weakness and wasting of other muscles in the upper limb, especially of biceps and supinators, may also be present, but weakness or loss of abduction of the shoulder is a specific, considerable, and easily recognisable disability. On the other hand, when recovery occurs it is easy to demonstrate.

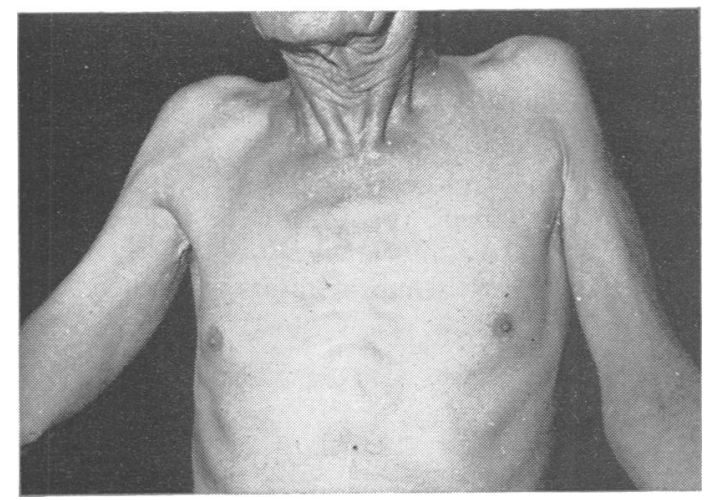

FIG. 1 Shoulder girdle wasting and weakness (bilateral).

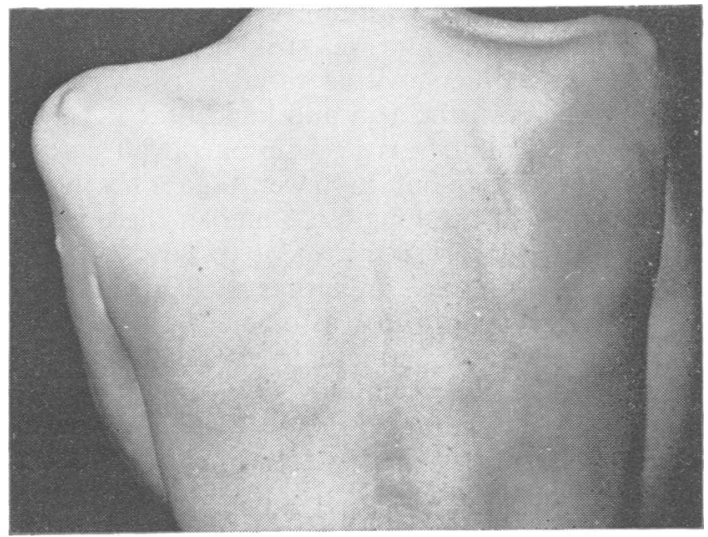

FIG. 2 Shoulder girdle wasting and weakness.

\section{PATIENTS}

Out of 253 inpatients with cervical spondylosis with neurological complications treated in the Bristol Neurosurgical Unit over the past 15 years the incidence of shoulder girdle muscle involvement (40 cases in all) was one in six cases of myelopathy (where lower limbs were affected) and one in eight cases of brachial neuritis (Table 1). In the myelopathy group the significant intervertebral disc lesion, as judged by myelography, in 28 out of 32 cases was at $C$ 3/4 intervertebral space (alone in 10 cases and with lower discs also judged abnormal in 18). In the eight cases with brachial neuritis there were two with apparently single disc lesions (at $\mathrm{C} \mathrm{4/5}$ and C 5/6 disc levels respectively), and the other six had multiple disc abnormalities between $\mathrm{C} 3 / 4$ and C 6/7 intervertebral spaces. 
TABLE 1

DETAILS OF 40 CASES OF WEAKNESS AND WASTING OF SCAPULAR AND DELTOID MUSCLES ASSOCIATED WITH CERVICAL SPONDYLOSIS

\begin{tabular}{lcc}
\hline & $\begin{array}{c}\text { Myelopathy } \\
(n=32)\end{array}$ & $\begin{array}{c}\text { Brachial } \\
\text { neuritis } \\
(n=8)\end{array}$ \\
\hline Incidence & $32 / 190$ & $8 / 63$ \\
Predominant level & $\mathrm{C} 3 / 4^{*}$ & $\mathrm{C} 4 / 5,5 / 6$ \\
Average age (years) & 59 & 57 \\
Average duration of symptoms (months) & 12 & 9 \\
\hline
\end{tabular}

* In 28 out of 32 cases.

By definition, all cases here described had motor loss (weakness and wasting). This was confined to the shoulder girdle and was striking in 14 cases and less so in the others, with a variable involvement of other muscles in the arm and hand (Table 2). Pain in the upper limb was a symptom in all cases of brachial neuritis, but in fewer than one in four of the cases of myelopathy. Notably, there was no upper limb sensory impairment in nearly half the cases and variable impairment, inadequate for neurological localization, in others. Sensory loss in the fifth cervical dermatome (deltoid area) was present with certainty in only six cases.

Cloward's operation (removal of intervertebral disc and adjacent bone, including osteophytes and overlying soft tissue projecting into the spinal canal, by an anterior approach, with a bone graft tapped

TABLE 2

SYMPTOMS AND SIGNS IN 40 CASES OF SHOULDER GIRDLE MUSCLE INVOLVEMENT ASSOCIATED WITH CERVICAL SPONDYLOSIS

\begin{tabular}{lcc}
\hline & $\begin{array}{c}\text { Myelopathy } \\
(n=32)\end{array}$ & $\begin{array}{c}\text { Brachial } \\
\text { neuritis } \\
(n=8)\end{array}$ \\
\hline Pain & 7 & 8 \\
Motor loss* & 10 & 4 \\
$\quad$ Severe & 8 & 3 \\
Moderate & 14 & 1 \\
Slight & 13 & 5 \\
Sensory loss & 7 & 1 \\
None & 2 & - \\
Hand only & 4 & - \\
Hand, forearm & 6 & 2 \\
Hand. arm & 6 & \\
\hline
\end{tabular}

* Weakness and wasting of shoulder, loss of abduction. into the half-inch $(1.3 \mathrm{~cm})$ drill hole) was performed in all cases except in five cases of myelopathy early in the series, in which laminectomy was done. Recovery of shoulder function (principally abduction) was good in over half the cases, follow-up being for periods ranging from six months to six years (Table 3). Most striking was the improvement in 15 cases of shoulder abduction, which was apparent usually the day after operation or at least within the next day or two. In eight other cases it was apparent at the first out-patient review (six to eight weeks after operation). Further recovery in these cases was progressive over weeks or months. In the cases that did not improve the condition did not deteriorate further over periods of one to three years, apart from two patients, aged 68 and 69 years respectively, with severe disability of two and five years' duration who died postoperatively with pulmonary oedema and pulmonary embolism.

TABLE 3

RESULTS OF OPERATION IN 40 CASES

\begin{tabular}{lcc}
\hline & $\begin{array}{c}\text { Myelopathy } \\
(n=32)\end{array}$ & $\begin{array}{c}\text { Brachial } \\
\text { neuritis } \\
(n=8)\end{array}$ \\
\hline Good recovery* & 17 & 6 \\
Improvement beginning: & 10 & 5 \\
Immediately & 7 & 1 \\
Within 2 months & 3 & -2 \\
Limited improvement & 12 & 2 \\
\hline
\end{tabular}

* Recovery of power in shoulder muscles, particularly of abduction.

As might have been expected, the patients showing recovery were on average somewhat younger and, more significantly, the average duration of their preoperative shoulder girdle weakness (in the myelopathy group) was nearly three times shorter than the cases without recovery (Table 4).

TABLE 4

PROGNOSIS OF OPERATION IN MYELOPATHY GROUP

\begin{tabular}{lcc}
\hline Recovery & $\begin{array}{c}\text { Average age } \\
\text { (years) }\end{array}$ & $\begin{array}{c}\text { Average duration } \\
\text { of disability } \\
\text { (months) }\end{array}$ \\
\hline Good & 56 & 6 \\
None & 62 & 16 \\
\hline
\end{tabular}




\section{DISCUSSION}

The reported incidence of particular cervical disc lesions differs in segmental cord and root involvement in myelopathies, with compression of the neurone in the cord, and in brachial neuritis, with compression more distally in the nerve roots, though the motor abnormalities observed in the upper limb and shoulder are the same. The relative lack of sensory impairment is consistent with pressure mainly on the anteriorly placed motor elements.

Necropsy of spinal cords compressed by the ridges produced on the anterior wall of the cervical spinal canal by disc degeneration, osteophytes, and overlying cartilage and ligaments shows the obliquity of nerve roots, which accounts for cord involvement at a lower segmental level than the disc pressing on it (Fig. 3). Also to be noted are the indentations on the anterior aspect of the cord, which lie almost exclusively between the exit points of adjacent motor rootlets from the cord. Also, at least in cases coming to necropsy (almost exclusively those with the myelopathy syndrome), the roots within the spinal canal between their exit from the cord and their entry into the intervertebral foramina do not seem to be so liable to compression or, if so, only at the most lateral extremities of the ridges. Therefore in cases of cord compression the nerve roots will be compressed only when the ridges are well marked laterally. In cases of brachial neuritis without cord involvement the ridges are not centrally prominent but must invade the canal laterally or project actually into the intervertebral foramina. Necropsy studies in these cases are rare. Straight radiography in vivo may show lateral osteophytosis. Myelography may be helpful but may show little or no abnormality. In cases of compression in the intervertebral foramina one might expect

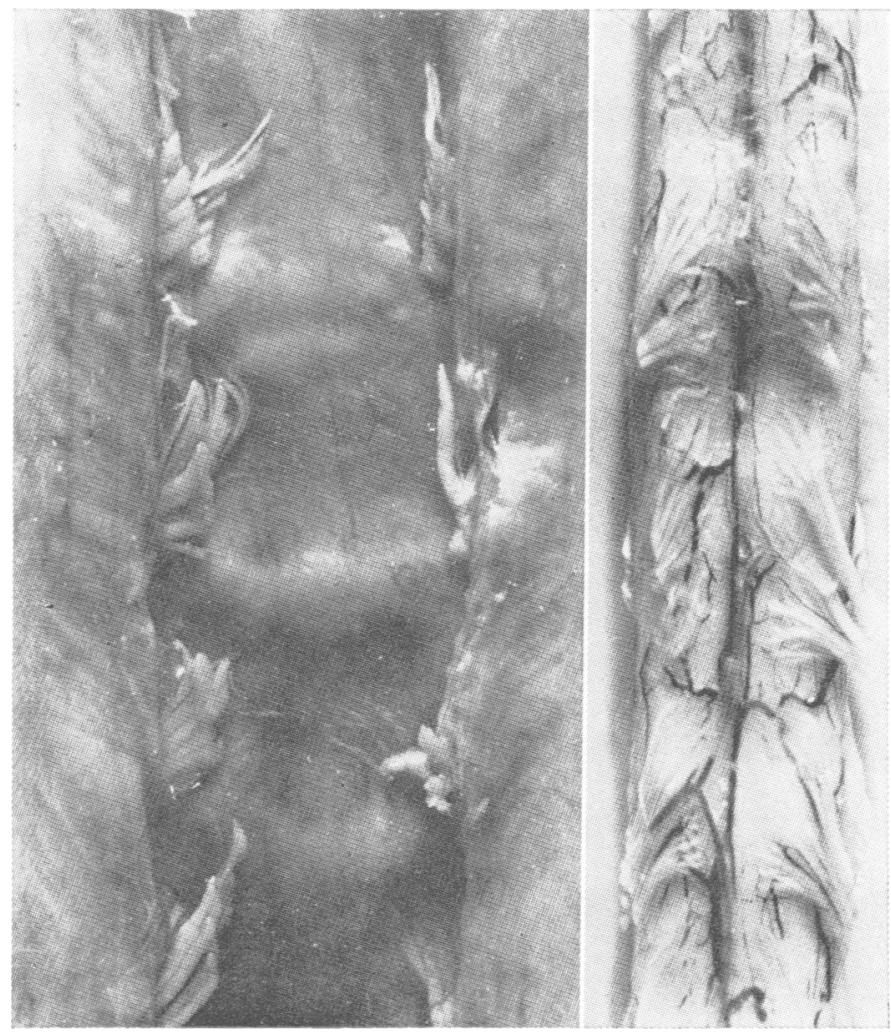

FIG. 3 Cervical spondylosis and cord compression (Brownell and Hughes, 1966). 
the whole nerve root to be compressed, but with the shoulder girdle discs at least sensation (that is, at the C 5 dermatome) is uncommonly affected.

The Cloward's operation, being confined to the relief of spinal compression at specific disc levels, as may be shown by serial myelographies, affords an opportunity of checking myelographic findings against subsequent neurological recovery. The results have in general vindicated the policy of reliance on these findings, especially when, as noted in so many cases, the start of recovery could be demonstrated (and, indeed, often was first noted by the patient) immediately after the operation. One must assume in such cases that most of the neurones in the affected segment or segments have not completely degenerated owing to long or severe compression. Some, being only lightly compressed, will account for the evidence of recovery immediately postoperatively, and others, rather more severely affected but still recoverable, will function again as time goes by. Yet others, which have been long and more severely compressed, will not recover.

There is a strong case for early diagnosis, accurate assessment, and radical treatment without too much delay. Alternative diagnoses of peripheral nerve or muscle disorder such as neuralgic amyotrophy and motor neurone disease are readily made, though not easily proved, and lead to no available treatment. They should not be made without first considering whether cervical spondylosis might account for the disorder. If loss of function is allowed to continue too long it will become irremediable, especially in this situation where the supraspinatus and deltoid muscles work at a mechanical disadvantage in lifting the arm. The prompt recovery that has ensued in most of the cases described here is all the more striking.

I thank the publishers and Drs Betty Brownell and J. T. Hughes for permission to reproduce Fig. 3.

\section{REFERENCES}

Brownell, B., and Hughes, J. T. (1966). Necropsy observations on the damage to the nervous system in degenerative disease of the cervical spine. Proceedings of the Fifth International Congress of Neuropathology, pp. 551-554. Excerpta Medica: Amsterdam.

Phillips, D. G. (1975). Upper limb involvement in cervical spondylosis. Journal of Neurology, Neurosurgery, and Psychiatry, 38, 385-390. 